\title{
Do doctors attending sexual-offence victims have to notify sexual-offence suspects that their patients who were forced to have unprotected sexual intercourse are HIV-positive? What should doctors do?
}

\author{
D J McQuoid-Mason, BCom, LLB, LLM, PhD \\ Centre for Socio-Legal Studies, Howard College School of Law, University of KwaZulu-Natal, Durban, South Africa
}

Corresponding author: D J McQuoid-Mason (mcquoidm@ukzn.ac.za)

\begin{abstract}
The question has been asked as to whether doctors attending sexual-offence victims have to notify sexual-offence suspects that their patients who were forced to have unprotected sexual intercourse are HIV-positive. It is submitted that the common law requires doctors to warn endangered third parties where such persons may suffer injury as a result of interactions with their patients, and that this applies to patients who have tested positive for HIV. The ethical rules of the Health Professions Council of South Africa also require doctors to breach the confidentiality rule against the consent of their patients who have tested HIV-positive, where the sexual partner of a patient is known, and after counselling such patients still refuse to allow disclosure - provided there is no risk of consequential harm to such patients. The dilemma of doctors treating HIV-positive patients is sometimes resolved where, in terms of the Criminal Law (Sexual Offences and Related Matters) Amendment Act No. 32 of 2007, a court order for the compulsory testing of the suspect has been obtained and the suspect knows his or her HIV status. Recommendations are made for what doctors should do in such cases.
\end{abstract}

S Afr J Bioethics Law 2017;10(2):67-69. DOI:10.7196/SAJBL.2017.v10i2.602

I was recently asked whether it is a doctor's duty when attending to sexual-offence victims to notify suspected sexual-offence perpetrators that their patients who were forced to have unprotected sexual intercourse were HIV-positive. It was said that this question has arisen because there is no legislation or court case directly on the subject. The question, however, can be answered by examining: (i) the common-law duty to warn endangered third parties; (ii) the provisions of the Criminal Law (Sexual Offences and Related Matters) Amendment Act No. 32 of 2007 (hereafter referred to as the Sexual Offences Act) ${ }_{i}^{[1]}$ and (iii) the ethical rules and guidelines of the HPCSA.

\section{Common-law duty to warn endangered third parties}

At common law, traditionally there was no general duty to act unless a person: (i) had created a dangerous situation through their prior conduct; (ii) was in control of a dangerous object; (iii) held public office; (iv) was in breach of a statute; or ( $v$ ) was in a special relationship with another. ${ }^{[2]}$

These categories were later expanded to include a wider test that imposed liability if the legal convictions of the community would have been outraged if the person in question failed to act. ${ }^{[2]}$ Since the advent of democracy, the courts have indicated that the legal convictions of the community must be informed by the provisions of the Constitution. ${ }^{[3,4]}$ While these categories provide useful guidelines, they are not fixed, and the courts tend to take a flexible approach. ${ }^{[2]}$ The most useful approaches to determine whether or not there is duty on doctors to inform suspects that their patients who were forced to have unprotected sexual intercourse with such suspects were HIV-positive are those of a 'special relationship' and 'the legal convictions of the community as informed by the Constitution'.

\section{Special relationship}

An example of a special relationship is the doctor-patient relationship, and the duty on doctors to treat their patients with the skill and care of a reasonably competent doctor in their branch of the profession. ${ }^{[5]}$ There is also a special relationship between doctors and persons who are not their patients but who require emergency medical treatment. ${ }^{[6]}$ It is submitted that doctors also have a special relationship with persons who may be harmed as a result of conduct by their patients, and that in such circumstances, doctors have a duty to warn endangered third parties who may be injured by their patients. ${ }^{[7]}$ Therefore, where a doctor knows that his or her HIV-positive patient has had unprotected sexual intercourse with a known partner, there is a legal duty on the doctor to counsel the patient to warn such partner and to take precautions, failing which there is a duty on the doctor to warn the partner. ${ }^{[7]}$ This duty is also provided for in the HPCSA guidelines ${ }^{[8]}$ mentioned below. While the courts are not bound by the general practices and guidelines of the professions, they will usually give due weight to them when judging whether or not practitioners have acted as reasonably competent members of their profession would act. $^{[5]}$ 


\section{Legal convictions of the community as informed by the Constitution}

The Constitution ${ }^{[3]}$ provides that everyone has a right to bodily and psychological integrity (section 12(1)), and that nobody may be refused emergency medical treatment (section 27(3)). The nature of medical practice and the ethical obligations imposed on members of the profession by the $\mathrm{HPCSA}_{1}^{[8]}$ measured against the right to bodily and psychological integrity in the Constitution, can give an indication of what the legal convictions of the community would expect from doctors. Thus it can be argued that the legal convictions of the community, as informed by the Constitution, ${ }^{[3,4]}$ would be outraged if a doctor, knowing of a patient's HIV-positive status, did not inform the alleged perpetrator of a sexual offence, who was at risk of contracting HIV, that he or she should get tested to avoid compromising their bodily and psychological integrity. If the alleged perpetrator is HIV-negative and needs to be put on post-exposure prophylaxis (PEP) within 72 hours of the alleged offence, this can be regarded as a need for 'emergency medical treatment. ${ }^{\prime[]}$ Likewise, therefore, it can be argued that the legal convictions of the community, as informed by the Constitution, would impose a legal duty on the doctor concerned to advise the alleged perpetrator to get tested within the 72-hour period. ${ }^{[9]}$

In summary, therefore, it seems that at common law - whether applying the special-relationship principle or the legal convictions of the community, as informed by the Constitution, principle - a legal duty will be imposed on doctors treating HIV-positive victims of sexual offences to advise the alleged perpetrators to undergo an HIV test if their patients may have exposed the suspects to HIV infection.

\section{Legal duties imposed under the Sexual Offences Act}

Most of the duties imposed under the Sexual Offences Act ${ }^{[1]}$ (Section 36) and the National Instruction issued in terms of the act ${ }^{[10]}$ by the National Commissioner of the South African Police Service protect the rights of the victims of alleged sexual offences. However, some provisions also protect the rights of alleged perpetrators, such as the right to confidentiality when a court order is granted compelling suspects to undergo HIV tests ${ }^{[1]}$ (section 36 ) and when the results of the tests are known (section 37).

In terms of the Sexual Offences Act, ${ }^{[1]}$ an application may be made to a magistrate for the compulsory testing of an alleged sexual-offence perpetrator by the victim, or an interested person on their behalf (section 30(1)). Where the application for compulsory HIV-testing was made by the victim or an interested person, the investigating officer must hand the sealed record of the test results to such person and the alleged offender, which must be kept confidential. The officer must also provide the prescribed information on the confidentiality of, and how to deal with, the HIV results, and if necessary, explain their contents (section 33(1)).

The act further provides that if an application for compulsory testing is made and the HIV status of the suspect is positive, the victim or the interested person acting on their behalf will be notified and will be able to discuss PEP with the victim's examining doctor (section 28). The examining doctor is legally required to ensure that, where necessary, the victim receives free PEP at a public health establishment, as well as free medical advice concerning the administering of such PEP (section 28). This will include establishing whether the victim wishes to undergo an HIV test to decide whether or not she or he should engage in PEP treatment, and then liaising with the police regarding the support required for the victim.

The police National Instruction ${ }^{[10]}$ deals mainly with the duties of police officers in the context of victim assistance (section 5). It provides for the medical examination of the alleged perpetrator, but there is no mention of testing him or her for HIV, as this is dealt with in the compulsory-testing provisions of the Sexual Offences Act. ${ }^{[1]}$ The medical examination of the suspect in the National Instruction is concerned with the collection of evidence from the body of the suspect, to establish his or her bodily features and to get blood samples for DNA analysis (section 16). Where no application has been made for the compulsory testing of the suspect and the victim tests positive for HIV, it is submitted that the victim's examining doctor - if he or she is not the same doctor who examines the suspect - should inform the suspect's examining doctor that such doctor should advise and counsel the suspect to undergo an HIV test if the latter does not know their HIV status.

In summary, the provisions of the Sexual Offences Act $^{[1]}$ are of assistance when a compulsory HIV test has been ordered by the court, because both the alleged perpetrator and the victim will know the suspect's HIV status. If the suspect's HIV test is positive and the victim's test is negative, she or he must be offered PEP and medical advice at state expense, and there is no need to inform the suspect. Conversely, it is submitted that if the victim's HIV test is positive, and the suspect has not been subjected to a court-ordered HIV test and does not know his or her status, and the victim's examining doctor is also the suspect's examining doctor, such doctor needs to advise the suspect to undergo an HIV test, and if the result is negative, to take PEP. If the victim is HIV-positive, and the victim's examining doctor is not also the suspect's examining doctor, the former must advise the latter to counsel the suspect on the need for him or her to undergo an HIV test.

\section{Ethical rules and guidelines of the HPCSA on HIV}

The ethical rules of the HPCSA provide a broad framework for ethical practice by practitioners registered with it. ${ }^{[8]}$ In addition, the HPCSA has produced a series of booklets that provide guidance to practitioners by expanding on the provisions in the ethical rules. Booklet 11 covers Ethical Guidelines for Good Practice with Regard to HIV. ${ }^{[1]]}$ These guidelines state that ' $[t]$ he decision to divulge information relating to the HIV status of a patient must always be done in consultation with the patient' (para 5.4).

The guidelines, however, state that it is good clinical practice for health practitioners to encourage their HIV-positive patients to disclose their status to their sexual partners, so that the latter can get tested and access treatment if necessary (para 9.1). If patients refuse consent, healthcare practitioners should use their discretion in deciding whether or not to make such disclosure to their patients' sexual partners 'taking into account the possible risk of HIV infection to the sexual partner and the risks to the patient (e.g. through violence) that may follow such disclosure' (para 9.2). In making the decision, health practitioners must consider the rights of all the parties concerned and take 'full responsibility' for their actions (para 9.2).

The guidelines provide that the health practitioner must: $(i)^{\prime}[c]$ ounsel the patient on the importance of disclosing to his or her sexual partner and on taking other measures to prevent HIV transmission'; (ii) 'provide 
support to the patient to make the disclosure'; (iii) '[i]f the patient still refuses to disclose his or her HIV status or refuses to consider other measures to prevent infection, counsel the patient on the healthcare practitioner's ethical obligation to disclose such information'; (iv) '[i]f the patient still refuses, disclose information on the patient's HIV status to the sexual partner and assist them to undergo testing and access treatment if necessary'; and ( $v$ ) must '[a]fter disclosure, follow up with the patient and the patient's partner to see if disclosure has resulted in adverse consequences or violence for the patient, and, if so, intervene to assist the patient appropriately' (para 9.2).

These requirements can be applied to the need to disclose a patient victim's HIV-positive status to a sexual-offence suspect who may have been exposed to HIV infection. It is submitted that the reference to a 'sexual partner' does not necessarily mean a person with whom the patient has had consensual sexual intercourse. The important requirement is that there must be an attempt to obtain the patient's consent, and then, if it is refused, to engage in proper counselling of the patient before deciding to make disclosure without consent.

\section{What should doctors do?}

Doctors should act in line with their common-law duty to protect endangered third parties - and to use the HPCSA guidelines - when deciding whether to disclose the HIV status of victims of sexual offences to suspects who have had unprotected sexual intercourse with HIV-positive victims. In such circumstances it is recommended that doctors should:

(i) counsel HIV-positive victims who allege that suspects have had unprotected sexual intercourse with them and who refuse consent for the examining doctor to disclose their HIV status that doctors are ethically and legally obliged to advise such suspects to have an HIV test, and that if the test is negative, to advise the suspects to request PEP;

(ii) inform suspects that the courts - and not the doctors - will decide on their guilt, but that if they have had unprotected sex with the victim they are strongly advised to have an HIV test, and if the tests are negative such suspects should request PEP. Suspects can decide whether or not they wish to follow the advice of the doctors; and

(iii) if the HIV tests of the suspects are negative, doctors should inform the SAPS that they need to ensure that such suspects are taken to clinics to undergo PEP treatment within 72 hours of the alleged offence. The police are obliged to do this because the courts have held that there is a legal duty on detaining authorities to provide the same level of care to persons in their custody as ordinary people who require antiretroviral treatment at public facilities. ${ }^{[12]}$

Acknowledgements. None.

Author contributions. Sole author.

Funding. None.

Conflicts of interest. None.

1. South Africa. Criminal Law (Sexual Offences and Related Matters) Amendment Act No. 32 of 2007

2. Minister van Polisie v Ewels 1975 (1) SA 590 (A)

3. Constitution of the Republic of South Africa, 1996.

4. S v Makanyane 1995 (3) SA 391 (CC).

5. Van Wyk v Lewis 1924 AD 438.

6. McQuoid-Mason DJ. When are doctors legally obliged to stop and render assistance to injured persons at road accidents? S Afr Med J 2016;106(6): 575-577. https://doi.org/10.7196/samj.2016.v106i6.10503

7. Tarasoff v Regents of the University of California (1976) Cal S Ct, 17 Cal Rep 3rd series 425 .

8. Health Professions Council of South Africa. Ethical and Professional Rules. Booklet 2. Pretoria: HPCSA, 2006.

9. McQuoid-Mason DJ, Dhai A, Moodley J. Rape survivors and the right to emergency medical treatment in order to prevent HIV infection. S Afr Med J 2003; 93(1): 41-44.

10. South African Police Service. National Instruction 3/2008 Sexual Offences. Government Gazette No. 31330, 15 August 2008.

11. Health Professions Council of South Africa. Ethical Guidelines for Good Practice with Regard to HIV. Booklet 11. Pretoria: HPCSA, 2008

12. Van Biljon v Minister of Correctional Services 1997 (4) SA 441 (C).

Accepted 5 July 2017 